E.L.U.A., 1, 1983, págs. 113-126

\title{
PUBLICIDAD Y CONNOTACIÓN: EL MENSAJE DE INFERENCIA
}

\author{
Emilio Feliu Garcia \\ (Universidad de Alicante)
}

En cualquier anuncio, por sencillo que parezca, se entrecruzan materias expresivas muy diferentes, múltiples informaciones y distintos niveles de percepción. Se mezclan en él varios mensajes. Por consiguiente, hablar de “mensaje publicitario» en relación a un anuncio es limitarlo en demasia; como señala G. Péninou, implica

«que no haya en el mensaje en cuestión más que un mensaje y que, además, sea de naturaleza publicitaria. Ahora bien, aún siendo exacto que todo mensaje publicitario es uno, sólo lo es en cuanto totalidad física singular, pese a lo cual no es ni mucho menos único; en un mensaje de la publicidad existe siempre una coexistencia de varios mensajes, algunos de los cuales son necesarios (es decir, necesariamente presentes) y otros facultativos ( $y$ por tanto, pueden no ser emitidos)" (1).

Al soporte del mensaje o sustancia informativa (anuncio, cartel...) Io llama Péninou manifiesto. Un manifiesto publicitario estará compuesto por una pluralidad de mensajes distintos y de diferente función dentro del mismo:

(1) G. PENINOU (1972) Semiótica de la Publicidad. G. Gili. Barcelona, 1976. Pág. 50. 
$M_{1}$ mensaje de pertenencia al género

$M_{2}$ mensaje de referencia al emisor

$M_{3}$ mensaje escritural

$\mathrm{M}_{4}$ mensaje icónico

$M_{5}$ mensaje de inferencia

Mientras que el primero pertenece al Plano de la Identidad, y los tres siguientes al de la Denotación, el mensaje de inferencia $\left(M_{5}\right)$ se inscribe en el Plano de la Connotación, siendo su función característica la creación del valor del objeto, y constituyendo, en esencia, un mensaje psicológico.

El mensaje de la connotación difiere en muchos aspectos de los mensajes del plano de la denotación. Mientras éstos son físicamente repertoriales, el de inferencia no es autónomo, puesto que procede de aquéllos; es una virtualidad de los otros mensajes, que vienen a ser su soporte material. Su actualización·está condicionada por el receptor, primordialmente por su capacidad de inducción. Se trata de un mensaje abstracto que coincide con el mensaje de intención. Es al mismo tiempo conjetural y plurivoco. Tratándose de un mensaje hipotético, las posibilidades de interpretación son tales que raramente la relación significante/significado es univoca. Siendo, pues, un mensaje de lectura interpretativa, podemos afirmar que tiene una estructura abierta (2).

La connotación, en cualquiera de sus manifestaciones (3), supone siempre un alejamiento de los lenguajes neutros y una ampliación de la significación, añadiendo unos valores suplementarios o adicionales, que pueden revestir (aunque no necesariamente) carácter afectivo. Si bien es cierto que la expresión de una idea nunca está totalmente desprovista de un tinte emotivo (4) y que ureducir el lenguaje a la neutralidad, si pudiera ser un objetivo realista, resultaría en la total destrucción de la poesía y la literatura" (5), hay ocasiones en que el empleo de formas provistas de cierta "coloración emotiva» adquiere especial relevancia. Max Black (6) postula la necesidad de distinguir entre la influencia emotiva de las palabras y enunciados y su posible

(2) Cfr. U. ECO (1968) La estructura ausente. Lumen. Barcelona, 1972.

(3) Más adelante recogemos la tipología de connotaciones establecida por K. Bochmann en «Valeurs connotatives du texte publicitaire». Langue Francaise, 28: 29-38.

(4) Cfr. J. VENDRYES (1923) Le langage. Introduction linguistique à l'histoire. Albin Michel. Paris, 1968.

(5) M. BLACK (1968) El laberinto del lenguaje. Monte Avila Ed: Caracas, 1969. Pág. 170. 
significado emotivo, según tengan capacidad de afectar los sentimientos del receptor o de transmitir información acerca de los del emisor. Charles L. Stevenson, por su parte, reconoce que "los términos emotivos iluminan brillante o tenuemente - por decirlo asi- a los sujetos de los que se predica y, de este modo, mueven a las personas a cambiar sus actitudes" (6).

Teniendo en cuenta que la función primordial en todo manifiesto publicitario es la implicativa, se comprende el valor esencial que adquieren los elementos emotivos y, generalizando, connotativos.

Dado este carácter implicativo, y el hecho de que la elección de productos o marcas obedece, al menos en parte, al "désir d'exprimer notre personalité telle qu'elle est" (7), la publicidad debe abandonar la mera exposición de las características funcionales del objeto y esforzarse en poner de relieve las significaciones simbólicas del mismo. La imagen en particular debe desempeñar una función relevante en este sentido, puesto que, entre otras muchas, tiene la ventaja de que puede operar a nivel de motivaciones profundas: su poder persuasivo reside en su capacidad de influir sobre el inconsciente. El lenguaje, por contra, responde a unas estructuras lineales que condicionan la forma de percepción, que se ve tamizada en mayor medida por la razón.

Por otra parte, "no todo lo que veo en las fotografias es lo mismo que puedo ver en la realidad directamente" (8), pudiendo observarse en ellas dos clases generales de signos:

-unos signos literales, de la productividad, de la identidad o semejanza;

-y unos signos abstractos, morfemas y signos no perceptibles en la visión directa de la realidad y sí en la imagen; signos que son atribuibles a fenómenos técnicos, ópticos o químicos, del medio fotográfico).

Estos elementos especificamente fotográficos no son considerados generalmente como signos, sino como parásitos interpuestos entre la realidad visible y su imagen; sin embargo nos parece, teniendo en cuenta

(6) Ch. L. STEVENSON (1971) Etica y Lenguaje. Paidós. Buenos Aires.

(7) D. VICTOROFF (1973). "Intterprétation motivationiste de l'image publicitaire». Bull. de Psychologie, XXVI, 3 07: 776-779.

(8) JOAN COSTA (1981). «EI lenguaje fotográfico: un análisis prospectivo de la imagen fotográfica», en Imágenes y lenguaje. Ed. Fontanella. Barcelona. Pág. 125. 
el uso que de ellos se hace, que a menudo se convierten en eficaces elementos estéticos, constituyendo una clase dentro de los recursos sintácticos de las "deformaciones", manipulaciones, que le confieren a la imagen parte de sus valores connotativos.

No obstante, el mensaje de inferencia no se desprende únicamente del mensaje icónico. También se da la transformación $M_{3} \rightarrow M_{5}$; es decir que el mensaje escritural posee igualmente la capacidad de contener un mensaje de inferencia. Al margen de lo que $\mathrm{M}$. Black denomina decir implícito, que en la mayoría de sus manifestaciones sería objeto de la Paralingüística, podemos referirnos a la suposición y la presuposición, que son creaciones de un universo de discurso.

Mediado el año de 1982, la Dirección General de Tráfico y R.E.N.F.E. lanzaban una campaña de seguridad en pasos a nivel cuya componente escrita decía:

\title{
ANTE UN PASO A NIVEL DETENGASE Y MIRE
}

Con el plan de supresión actualmente en marcha, RENFE va a eliminar más de 750

pasos a nivel. Con la colaboración de Ayuntamientos y Diputaciones esta cifra podría duplicarse. Pero, usted, conductor, también tiene que colaborar con este plan.

Cumpla con su deber. Ante un paso a nivel, deténgase y mire

\author{
CAMPAÑA DE SEGURIDAD \\ EN PASOS A NIVEL \\ ES UN MENSAJE DE LA DIRECCION \\ GENERAL DE TRAFICO Y RENFE
}

La imagen representa una carretera en dirección al fondo cortada por un paso a nivel sin barreras en el momento en que un tren pasa velozmente de izquierda a derecha; los árboles que se encuentran al borde de la vía presentan una clara inclinación; en un plano medio, y a la derecha de la carretera, una señal de peligro con varias leyendas.

La imagen en cuestión contiene varios elementos connotadores: las franjas horizontales que atraviesan toda la escena a la altura de la vía; la inclinación de los árboles; la señal de peligro; las relaciones direccionales 
objeto móvil/carretera, carretera/mirada del lector, objeto móvil/mirada del lector. De los dos primeros se desprende el paso de un objeto (de considerables dimensiones) a gran velocidad; la existencia de la señal de peligro denota que se trata de un tren. Aquéllos connotan el tipo de tren de que se trata (moderno, por el diseño del rastro, y rápido); la señal no sólo denota la existencia de un peligro, contiene un valor suplementario, adicional, que le viene dado por su carácter redundante: la acumulación de varios significantes, las leyendas (paso sin guarda, ojo al tren doble vía, atención al tren), para un sólo significado, tendente a conferirle una influencia emotiva. Por último, las relaciones direccionales tienen una clara función implicativa, que se ve reforzada por la naturaleza del encabezamiento lingüístico. Encontramos, pues, un claro mensaje de inferencia que tiene como sustento material un mensaje icónico $\left(\mathrm{M}_{4} \rightarrow \mathrm{M}_{5}\right)$.

Pero el manifiesto incluye otro (u otros) cuya base es el mensaje escritural $\left(M_{3} \rightarrow M_{5}\right)$. En efecto, del encabezamiento ( Ante un paso a nivel deténgase y mire") se infiere el mismo $M_{5}$ que encontrábamos anteriormente contenido en $M_{4}$. $Y$ encontramos, además, otro mensaje implícito en el texto; mensaje éste que depende en mayor medida de la capacidad interpretativa del lector. Podemos descomponer el contenido del texto de la siguiente forma:

(i) Renfe va a eliminar más de 750 pasos a nivel.

(ii) Con la colaboración de Ayuntamientos y Diputaciones esta cifra podría duplicarse

(iii) Usted también tiene que colaborar

(iv) Cumpla con su deber.

De los tres últimos enunciados se deduce que "los Ayuntamientos y Diputaciones no cumplen con su deber". Este sería el mensaje de inferencia, cuya clave reside en el uso del condicional irreal, subrayado en (ii).

Con respecto a la implicación material, indica $O$. Ducrot que cafirmar ' $p \Rightarrow q$ ' es simplemente excluir la posibilidad de que ' $p$ ' sea verdadero, y ' $q$ ' sea falso" (9). Atribuyendo a ' $p$ ' y ' $q$ ' los criterios de verdadero/falso, tendríamos las siguientes posibilidades:

(9) O. DUCROT (1972) Dire et ne pas dire. Hermann. Paris. 


$\begin{array}{cccc} & p & q & p \Rightarrow q \\ 1 & V & V & V \\ 2 & V & F & F \\ 3 & F & V & V \\ 4 & F & F & V\end{array}$

Afirmar ' $p \Rightarrow q$ ' significa indicar que se encuentra en una de las situaciones $1,3,4$, y que no está en 2; es decir que si ' $q$ ' es falso, ' $p$ ' no puede ser verdadero. Pues bien, sea ' $p$ ' la "colaboración de Ayuntamientos y Diputaciones», y ' $q$ ' la «duplicación de esta cifra»:

Si $p$

Con la colaboración.... entonces q

Se duplica esta cifra

Al presentarse ' $q$ ' bajo la forma de un condicional irreal, tenemos que ' $q$ ' es falso; luego ' $p$ ' lo será igualmente. Por lo tanto,

(ii') Los Ayuntamientos y Diputaciones no han colaborado.

Pero no acaba ahí el mensaje de inferencia. En (iii) teníamos que «usted también está obligado a colaborar». ¿Quién, además de usted, está obligado a colaborar? ¿A quién incluye "también»? Parece incuestionable que a los Ayuntamientos y Diputaciones. Luego

(iii') Los Ayuntamientos y Diputaciones tienen que colaborar con este plan.

Finalmente, en (iv) parece decirse — después de todo lo visto- «Cumpla con su deber. No haga como los Ayuntamientos y Diputaciones».

Ahora bien, ¿cómo justificar el contenido de este $\mathrm{M}_{5}$ ? No hay que olvidar el contexto político en que aparece el manifiesto, así como el sujeto y el objeto de la crítica subrepticiamente deslizada en el mismo. Recordemos, por otra parte, que la campaña surge en los meses inmediatamente anteriores a las últimas elecciones legislativas.

En la rúbrica del manifiesto aparecen la Dirección General de Tráfico y Renfe; siendo la primera una institución del Estado, y la segunda un monopolio estatal, ambas dependen del Gobierno central. Ayuntamientos y Diputaciones son corporaciones locales, a la sazón gobernadas en su mayoría por el partido que lideraba la oposición al Gobierno en las instituciones legislativas del Estado, y que se perfilaba como la 
más firme alternativa de poder en las ya casi inminentes elecciones. Tenemos, en consecuencia, que en $\mathbf{M}_{5}$ la Administración Central (gobernada por un partido político, $X$ ) critica la actuación de las instituciones locales (regidas por otro partido, $Y$ ).

El mensaje de inferencia, inmerso en una perspectiva pragmática (en relación con el emisor y el receptor —próximos electores-, así como con las condiciones de la emisión), muestra claramente cómo un manifiesto publicitario (de publicidad institucional) puede confundirse (o, mejor, fundirse) con un mensaje propagandístico. Publicidad y propaganda aparecen aunados a través, precisamente, del mensaje de inferencia. Este ejemplo confirma, por otra parte, las características que al principio atribuiamos al mensaje de inferencia: se trata de un mensaje virtual, conjetural y plurivoco, que supone un alto grado de participación por parte del receptor.

Pero, al margen de estos mensajes de inferencia relativamente complejos, e intimamente relacionados con las presuposiciones, la connotación adopta muy diversas formas, que pasamos a considerar brevemente. El texto publicitario es, en principio, un texto lingüístico como cualquier otro, con un plano de la expresión y un plano del contenido; si bien se caracteriza por el empleo de una expresión grandilocuente y rebuscada, frente a un contenido a menudo banal. La fuerza de un texto publicitario no proviene de su contenido denotativo, sino de las connotaciones. Con una presentación atractiva, plagado de alusiones y sugestiones, no pretende tanto hacerse comprender como causar efecto.

Partiendo de los factores que intervienen en la comunicación, podemos establecer varios tipos de connotación (10); a saber: metalingüistica, poética, emotivo-evaluativa, conativo-apelativa y fática.

La connotación metalingüistica viene dada por los índices implícitos del enunciado que informan sobre la elección de un determinado código. Tiene gran importancia en la publicidad, y se basa en el empleo de elementos lingüísticos que se desvian del código establecido. La ampliación de los códigos de la publicidad puede llegar hasta la incorporación de elementos de otro código lingüístico, de otra lengua, aunque ésta es una de las formas más extremadas. Mucho más usual es la hipercaracterización ortográfica, "alteración de la grafía de una forma

(10) K. BOCHMANN op. cit.: 32. 
para que llegue a ostentar caracteristicas del sistema ortográfico de otra lengua» (11): Multielástic, Eristow \& limonow...

El prestigio de las ciencias y de la técnica es ampliamente explotado en los textos publicitarios mediante la adopción de algunos términos (sobre todo en los nombres de marca y en las partes descriptivas), alternando el tecni cismo auténtico con términos pretendidamente científicos:

\author{
servo-dirección, toma termostática de aire \\ electrolitos gelificados \\ transmitancia \\ poliinsaturados \\ intercomunicación electrónica integral.
}

En ocasiones pueden aparecer combinados barbarismo y tecnicismo: sistema «U loading», Seat Leasing, bi-fluoré.

Excepto en algunos de los casos, y siempre en función de los destinatarios, lo único realmente importante es la significación global, instalada a nivel connotativo, y que necesitaría para ser expresada denotativamente del empleo de neologismos como "anglicidad", "tecnicidad", etc. Cuando un término técnico, por demasiado frecuente, deja de connotar "tecnicidad", se opera sobre él alguna transformación que le pueda restituir su status de connotador. Así, "toma de aire» es una forma lexicalizada que tiene poco poder sugeridor de la sobresignificación pretendida; "toma de aire termostática" puede convertirse fácilmente, mediante un procedimiento próximo a la tmesis, en «toma termostática de aire", forma más analítica que la anterior, y, sobre todo, menos corriente, menos banalizada.

La elección de términos extranjeros es uno de los múltiples artificios evocadores que derivan su efecto no de una cualidad intrínseca, sino de estar asociados a un ambiente o un registro de estilo particulares. Los procedimientos metagráficos y léxicos que hemos señalado entran de lleno en este campo asociado a la estilística. También la sintaxis presenta múltiples recursos de este tipo: la inversión, que es rara en el lenguaje coloquial pero frecuente en contextos científicos y

(11) CH. PRATT (1973) «El lenguaje de los medios de comunicación: algunos aspectos». Filología moderna, 46/47: 63-87. 
literarios, puede llegar a ser considerada como propia de dichos registros, evocadora, por tanto, de tales contextos. Eso sin considerar el "efecto de incertidumbre creado por la inversión» (12).

La connotación poética utiliza de los más diversos procedimientos extrañadores de distinta naturaleza: fonéticos, morfológicos, sintácticos y semánticos. Procedimientos que sirven para subrayar el sentido de una expresión o para añadirle un segundo sentido. Este tipo de connotación surge «cuando un elemento semántico normalmente periférico, poco recurrente, subjetivo, o que indica solamente la facultad del semema de unirse a algún otro, está subrayado en el texto" (13); la relación entre el núcleo sémico normalmente dominante y la segunda significación (connotativa) aparece invertida. Así, por ejemplo, la metáfora hace que la significación denotativa se transforme en significación connotativa, en cuanto que el sentido transferido toma el lugar de la denotación. La metáfora, basada en un mecanismo de transferencia, se significa por la upreeminencia (y hasta por la exclusividad) que suele darse al término metaforizante sobre el objeto metaforizado" (14), por lo que resulta a menudo infra-referencial; acrecienta la originalidad del mensaje mediante una referencia exógena al objeto, del que únicamente selecciona el valor exaltado. Pero no todos los recursos productores de connotaciones poéticas están basados en la transferencia; muchos otros se limitan a señalar, enfatizándolo, el núcleo del mensaje. Los distintos artificios retóricos están al servicio de la producción de connotadores fundamentalmente poéticos (15).

La connotación emotivo-evaluativa expresa una actitud, verdadera o fingida, del emișor frente al objeto del mensaje. No se trata sólo de emociones, sino de una escala de diferentes actitudes manifestadas con el propósito de establecer una relación de confianza entre el productor y el consumidor. No hay que olvidar, a este respecto, los mecanismos de identificación de los receptores con el emisor aparente del mensaje, que puede aumentar considerablemente la eficacia de estos connotadores. La denotación emotivo-evaluativa viene expresada normalmente mediante palabras como «amar», "preferir»..., que representan, tanto o más que una actitud, una noción; la connotación está contenida, por ejemplo, en el empleo de diminutivos o aumentativos, en

(12) S. ULLMAN (1964) Lenguaje y estilo. Aguilar. Madrid, 1973. Pág. 126.

(13) K. BOCHMANN op. cit.: 31.

(14) G. PENINOU op. cit.: 96.

(15) Cfr. E. FELIU (1977) “Retórica y lenguaje publicitario" Item, 2: 39-51. 
las palabras fuertes o invectivas...; y también en formulaciones aparentemente neutras, pero que revelan una actitud polémica ("¿eres una esclava del hogar y estás contenta?). La coloración emotiva se hace imprescindible en toda publicidad predicativa (que es la que está íntimamente relacionada con los valores connotativos) en las dos posibilidades señaladas por M. Black y ya citadas anteriormente. Este doble aspecto indica de por sí que los elementos emotivo-evaluativos del lenguaje tienen muy a menudo un cierto carácter conativo.

La connotación emotivo-evaluativa está, pues, estrechamente ligada a la conativo-apelativa, constituida por todo lo que de manera implícita hace una llamada al receptor del mensaje, demandándole un cierto comportamiento. $Y$ si bien es cierto que la persuasión está basada en gran medida en la presentación favorable del objeto y, sobre todo, en las connotaciones poéticas, no hay que despreciar la importancia de la apelación al consumidor, sea explícita o no. En la mayoria de los casos no se trata únicamente de «mover a la acción de compra, sino también, en cierto modo, de imponer unos determinados comportamientos, una imagen del mundo y de sí mismo, que son a veces condición necesaria para la adquisición de ciertos objetos o servicios. La importancia de esa imagen de sí mismo justifica la abundancia de expresiones de referencia definidas generales cuando el referente es el destinatario.

Las funciones básicas de todo manifiesto publicitario son las de representación, apelación (implicación) y la poética, centradas, respectivamente, en el producto, el destinatario y el mensaje. Ya se ha señalado que la función poética es infra-referencial, ya que centra su atención sobre el mensaje mismo, reificándolo e incidiendo en su rendimiento estético. Quedan, pues, dos ejes en los que la referencia es fundamental: el del objeto y el del destinatario. La referencia al objeto se suele hacer a través de expresiones de referencia definida singular (16), tales como frases nominales definidas, nombres propios o pronombres. Incluso en el caso de que no se trate de un producto único, sino de distintas variedades dentro de una gama, la referencia se realiza generalmente a través de la marca (que adquiere entonces la función de expresión de referencia definida general (17). No obstante,

(16) Cfr. J. LYONS (1977), Semántica. Ed. Teide. Barcelona, 1980. Véase fundamentalmente el epigrafe 7.2: 169-188.

(17) La marca se comporta como un término plurívoco, pudiendo tener como referente tanto el producto concreto (individuo de una clase A), como las variedades del producto (clase A) o el fabricante (individuo de una clase B). 
también pueden asumir su referencia algunas frases nominales definidas, próximas a la categoría de los llamados títulos de referencia única: los símbolos y las construcciones antonomásicas, que a veces aparecen en aposición al nombre propio o a la representación gráfica del producto.

Respecto al destinatario, la referencia puede manifestarse mediante pronombres personales o ciertas formas verbales (el imperativo) que la hacen explícita, o a través de expresiones de referencia definidas generales, cuyo referente es una clase de individuos tomada como paradigma de la "imagen de sí mismo" que se trata de imponer al destinatario. Se trata de una referencia, además de implícita, indirecta; se puede considerar estas expresiones como portadoras de la connotación conativo-apelativa:

Apelación explicita

¿Conoce usted el tren?

Con sus amigos saque el más Long de los whiskies

Si no le salen las cuentas, abra una cuenta

\section{Apelación indirecta}

Los que llevan trajes Reval de pura lana...

Las personas con cuenta corriente...

Porque hay hombres que tienen suerte

...para el hombre moderno

...para hombres

Para apasionadas de la naturaleza.

Sólo en muy pocos casos se da la referencia genérica: en la publicidad institucional con cierto contenido ideológico, en la publicidad comercial de productos o servicios no destinados al consumo individual, además de la propaganda.

Existen también medios lingüisticos para atraer la atención de los destinatarios. Los connotadores fáticos retienen la atención por la desviación consciente de una norma, alejándose de las expectativas del receptor: efectos gráficos o acústicos sorprendentes, desvíos de la morfología y la sintaxis... Así, existen algunos casos de aliteración o rima en función fática ( $y$ no poética), que no tienen como finalidad el subrayar o debilitar la significación.

No resulta frecuente encontrar un enunciado que contenga sola- 
mente tal o cual especie de connotación; como en el caso de las funciones del lenguaje, se trata de una cuestión de jerarquias, de mayor o menor relevancia. Ahora bien, la diversidad de connotaciones está sometida a la función dominante del texto publicitario, que es, generalmente, la apelación. Es bastante usual que unos mismos elementos sustenten una amalgama de connotaciones diferentes.

Por último debemos hacer mención de lo que M. Black denomina mensaje implícito concentrado, recurso literario "mediante el cual el escritor hábil puede lograr economía de expresión, fuerza y juego múltiple de significados" (18). Tales mensajes implican que el lector posea un conocimiento previo de los objetos o acontecimientos aludidos en ellos para que de esta forma unas pocas palabras puedan suscitar un pensamiento complejo. Es éste uno de los fenómenos más frecuentes en la publicidad actual, siendo, los ejemplos abundantísimos:

(1) LA REVANCHA DE TRAFALGAR Sorry Gentlemen, os la hemos devuelto. $Y$ con una gran victoria a domicilio. Habéis tenido que reconocer, en el mismísimo London, que un gin español es tan bueno como los mejores del mundo. Es decir, los vuestros.

(2) Ha nacido una estrella.

(3) Mi buenos Passport querido.

La referencia implícita del texto está reforzada casi siempre por la componente icónica: la imagen del anuncio en que aparece (1) representa la batalla de Trafalgar; junto a (3) encontramos una panorámica de la capital argentina, en la que se aprecia el famoso «monolito". Por otra parte, cuando la referencia implícita es un enunciado, éste suele estar distorsionado, manipulado hasta un cierto, límite que permita su reconocimiento en el nuevo enunciado; la relación entre los enunciados implícito y explícito se establece no sólo en virtud de su analogía, sino además por la existencia de determinados rasgos prosódicos simbolizados a través de recursos tipográficos como el entrecomillado.

(18) M. BLACK op. cit.: 163. 
Dado que el rendimiento de este fenómeno condensador de mensajes está en función del conocimiento previo del lema original, la publicidad extrae muchos de sus mensajes implícitos del extensísimo repertorio de refranes, frases hechas y modismos con que cuenta nuestra lengua:

\author{
Oír para creer \\ Todos los caminos llevan a RAM \\ Siempre segundas Parker fueron buenas \\ A quien madruga Kodak le ayuda.
}

Esta modalidad de mensaje implícito tiene como finalidad -ajustándose a la definición dada por M. Black-, más que el juego múltiple de significados, la economía de la expresión y la fuerza, así como la facilidad de memorización y el poder de captación.

Pueden incluirse también entre los diferentes tipos de referencia implícita los procedimientos de actualización, de puesta en discurso, de lexías complejas, lexemas secundarios (19) reanalizados. En tales casos coexisten el sentido figurado de la estructura secundaria y el literal de las estructuras primarias derivadas del reanálisis:

¡No se pille los dedos! Taladrín.

¿Va usted a pagar los vidrios rotos? Lleve productos en envase sin vuelta.

El que lleva la voz cantante. Auto-radio Sanyo.

Olvide los malos tragos. Bebe poco y bueno. Magno.

Lectric Shave Williams le pone los pelos de punta para que su afeitadora los corte de raiz.

En estos últimos casos si entra en funcionamiento el juego múltiple de significados.

En virtud de lo implícito, de las connotaciones, de la inferencia en general, el manifiesto publicitario resulta un discurso que une a su rendimiento utilitario un rendimiento estético; un discurso constituido en ultra-signo; al que es consustancial la plurivocidad; un discurso, en suma, plural.

(19) Cfr. E. COSERIU (1977) Principios de Semántica estructural. Gredos. Madrid, 1981. Véase también M. POREBSKI (1970), «Images et signes», en Sign, Language and culture, Mouton. París: 203-223. 